\title{
A produção do conhecimento sobre risco e vulnerabilidade social como sustentação das práticas em políticas públicas
}

\author{
Knowledge production on risk and social vulnerability \\ as a means of supporting practices in public \\ policies of social psychology
}

\author{
Carolina dos REIS ${ }^{1}$ \\ Neuza Maria de Fátima GUARESCHI \\ Simone Maria HÜNING² \\ Marcos Adegas de AZAMBUJA $^{3}$
}

\begin{abstract}
Resumo
Este artigo tem por objetivo discutir a produção de conhecimento em Psicologia Social no Brasil sobre as temáticas de risco e vulnerabilidade social a partir de uma análise arqueogenealógica. Para isso, analisam-se os documentos produzidos pelos grupos de trabalhos vinculados ao campo da Psicologia Social e apresentados nos simpósios da Associação Nacional de Pesquisa e Pós-Graduação em Psicologia no período compreendido entre 1988 e 2010. Com a discussão sobre a produção de conhecimento pelos grupos de trabalho, pode-se visibilizar e discutir como os saberes que envolvem os temas de risco e vulnerabilidade social têm sustentado as práticas em políticas públicas no campo da Psicologia Social.
\end{abstract}

Palavras-chave: Políticas públicas; Produção de conhecimento; Psicologia social; Vulnerabilidade social.

\begin{abstract}
This article aims to discuss the history of knowledge production in the field of Social Psychology in Brazil about risk and social vulnerability by means of an archeo-geneologic analysis. The research involved an analysis of documents produced by working groups from the field of Social Psychology that were presented at symposiums of the National Association of Postgraduate Research in Psychology in the period from 1988 to 2010. On the basis of the working group discussions about knowledge production, it is possible to perceive and discuss how knowledge about risks and social vulnerability has supported practices in public policies in the field of Social Psychology.
\end{abstract}

Keywords: Public policies; Knowledge production; Social psychology; Social vulnerability.

$\nabla \nabla \nabla$

1 Universidade Federal do Rio Grande do Sul, Instituto de Psicologia, Programa de Pós-Graduação em Psicologia Social e Institucional. Av. Ramiro Barcelos 2600, Santana, 90035-003, Porto Alegre, RS, Brasil. Correspondência para/Correspondence to: N.M.F. GUARESCHI. E-mail:<nmguares@gmail.com>.

2 Universidade Federal de Alagoas, Instituto de Psicologia, Programa de Pós-Graduação em Psicologia. Maceió, AL, Brasil.

${ }^{3}$ Centro Universitário Franciscano, Curso de Psicologia. Santa Maria, RS, Brasil. 
Este estudo é resultado de uma pesquisa que teve por objetivo colocar em questão a produção do conhecimento em Psicologia Social no Brasil. Para tanto, no desenvolvimento da pesquisa, partiu-se de uma recusa da perspectiva histórica com a qual usualmente é narrada a construção desse campo, buscando-se o desenvolvimento de uma análise de inspiração arqueogenealógica, como desenvolvida pelo filósofo Michel Foucault (1979/2007). Isso significa abandonar a intenção de recuar no tempo para restabelecer uma continuidade que resultaria naquilo que se configura no presente, bem como assumir a pretensão de demarcar os acidentes, inversões e desvios que evidenciam não a unidade de uma história de um campo de saber, mas as suas fragmentações e heterogeneidades. A arqueogenealogia analisa, por um lado, as condições históricas de possibilidade de um saber e, por outro, o saber em termos de estratégias e táticas de poder. Assim, o saber não é compreendido como prática discursiva, mas inclui a relação das práticas não discursivas, ou seja, não se dissocia saber e poder (Foucault, 1969/2009). Portanto, entende-se que acompanhar a produção do conhecimento em Psicologia Social é perseguir os jogos de produção e desestabilização de determinadas verdades sobre o sujeito e o campo social, que operam construindo modos de ser e estar no mundo.

Assim, este trabalho se fundamenta na forma como o filósofo Michel Foucault colocou os saberes em análise para percorrer os movimentos que a produção do conhecimento nesse campo vai realizar em torno de determinados temas, que passam a ser reconhecidos e legitimados como aqueles relacionados à Psicologia Social. Ao optar por trabalhar a partir dos estudos produzidos acerca dessas temáticas, busca-se evitar recair na forma como tradicionalmente a história da Psicologia Social vem sendo apresentada, com a divisão de paradigmas na produção do conhecimento. Eles são, geralmente, dispostos de forma linear e cronológica, em uma perspectiva evolucionista, que parte do positivismo norte-americano até a abordagem pós-estruturalista, como se esta última fosse mais avançada epistemologicamente.

Esta pesquisa, conforme detalhado adiante, 584 analisa os resumos dos Grupos de Trabalho (GT) dos simpósios da Associação Nacional de Pesquisa e Pós-Graduação em Psicologia (ANPEPP). Após a leitura de todos os anais dos simpósios, foram selecionados os resumos de trabalhos dos GT em que circulam os enunciados que compõem, especificamente, o campo discursivo da Psicologia Social no Brasil. A inclusão e delimitação dos enunciados no campo da Psicologia Social foi sustentada pela própria descrição dos GT e de suas pesquisas, dada tanto pelas perspectivas teóricas e metodológicas, como pelos objetos de conhecimento, especificados nesses registros como concernentes à Psicologia Social. A partir da narrativa dos próprios GT sobre seus processos históricos nesses resumos, foram delineadas formações discursivas que orientaram e impulsionaram o conhecimento em Psicologia Social no País. Ao analisar os temas que passam a ser construídos nos domínios da Psicologia Social, buscou-se acompanhar como os processos históricos delineiam formações discursivas que, longe de seguir uma unidade de desenvolvimento contínuo e progressivo, produzem-se por rupturas e descontinuidades. Identificou-se que, ao longo dos simpósios realizados pela ANPEPP, vão emergindo grupos de trabalho que se caracterizam como pertencentes ao campo da Psicologia Social e direcionam as preocupações desse campo de saber para determinadas temáticas como objeto de estudo. Dentre essas temáticas, nas análises da pesquisa, destacam-se três como aquelas que transversalizam a produção do conhecimento em Psicologia Social: as noções de risco-vulnerabilidade, que englobam as práticas em políticas públicas, cidadania e direitos humanos; as identidades e tecnologias, pelas quais se distribui e se conflita uma gama de tecnologias de poder e saber sobre a categoria psicológica dos indivíduos, destacando-se as intervenções sobre as relações de sexo, raça e sexualidades; os processos de urbanização da sociedade, nos quais se encontram não somente as práticas que envolvem a organização do espaço urbano, mas também os modos de vida e os enunciados de globalização, industrialização, consumo e nomadismo. Neste artigo, apresenta-se tão somente a discussão específica realizada sobre os temas risco e vulnerabilidade social. 


\section{Método}

\section{Instrumentos}

Para o desenvolvimento deste estudo, foram tomados como material de pesquisa os documentos produzidos pelos grupos de trabalhos vinculados ao campo da Psicologia Social e apresentados nos simpósios da ANPEPP (2012) no período entre 1988 e 2010.

A Associação Nacional de Pesquisa e Pós-Graduação em Psicologia é uma entidade que congrega os programas de pós-graduação em Psicologia, em nível de mestrado e doutorado, legalmente reconhecidos pelo governo brasileiro. A principal característica da ANPEPP são os grupos de trabalho, responsáveis por discutir o desenvolvimento de políticas de produção do conhecimento científico na área da Psicologia, bem como a avaliação e divulgação dessas políticas. Os GT são formados por pesquisadores, professores da área de Psicologia e afins, que discutem, planejam e definem em conjunto os temas de interesse comum a serem investidos pelas pesquisas e produções científicas da Psicologia que circulam no País. Até o ano de 2010 a ANPEPP possuía 61 GT, que discutiam diferentes temáticas concernentes à Psicologia e envolviam 64 programas de pós-graduação, entre mestrados e doutorados vinculados à entidade.

Entre 1988 e 2010, a ANPEPP realizou 13 simpósios: I Simpósio, em Caruaru, em 1988; II Simpósio, em Gramado, em 1989; III Simpósio, em Águas de São Pedro, em 1990; IV Simpósio, em Brasília, em 1992; V Simpósio, em Caxambu, em 1994; VI Simpósio, em Teresópolis, em 1996; VII
Simpósio, em Gramado, em 1998; VIII Simpósio, em Serra Negra, em 2000; IX Simpósio, em Águas de Lindoia, em 2002; X Simpósio, em Aracruz, em 2004; XI Simpósio, em Florianópolis, em 2006; XII Simpósio, em Natal, em 2008; e XIII Simpósio, em Fortaleza, em 2010.

No Tabela 1 observa-se o crescimento no número de GT por simpósio da ANPEPP.

Nos anais de cada simpósio, encontram-se os resumos produzidos pelos GT contendo o histórico do grupo de trabalho, as propostas para os respectivos campos de estudos para os próximos anos e os resumos das pesquisas em desenvolvimento pelos membros dos GT que foram apresentadas ao grupo.

\section{Procedimentos}

Como referido anteriormente, os procedimentos de pesquisa tiveram início com a leitura de todos os resumos de cada simpósio realizado no período. Após esse processo, foram identificadas três grandes temáticas em torno das quais estavam sendo produzidos os trabalhos definidos como do campo da Psicologia Social (risco e vulnerabilidade social, identidades e tecnologias, processos de urbanização e globalização). Importante destacar que, algumas vezes, em um mesmo GT foi possível identificar produções sobre uma, duas ou mesmo três dessas temáticas. Do total de 16 GT que compõem o campo discursivo da Psicologia Social, foram selecionados 11 GT como aqueles cujo histórico, propostas e resumos assinalam os temas de risco e vulnerabilidade social. Tais temas dialogam com um conjunto de produções desses grupos as quais têm

Tabela 1

Crescimento dos GT ao longo dos Simpósios da ANPEPP

\begin{tabular}{|c|c|c|c|c|c|c|c|c|c|c|c|c|}
\hline \multicolumn{13}{|c|}{ Simpósios } \\
\hline I & $\|$ & III & IV & V & $\mathrm{VI}$ & VII & VIII & IX & $x$ & $X I$ & XII & XIII \\
\hline \multirow[t]{2}{*}{$1988^{*}$} & 1989 & 1990 & 1992 & 1994 & 1996 & 1998 & 2000 & 2002 & 2004 & 2006 & 2008 & 2010 \\
\hline & $9 \mathrm{GT}$ & $15 \mathrm{GT}$ & $14 \mathrm{GT}$ & $21 \mathrm{GT}$ & $28 \mathrm{GT}$ & $35 \mathrm{GT}$ & $30 \mathrm{GT}$ & $32 \mathrm{GT}$ & $41 \mathrm{GT}$ & $52 \mathrm{GT}$ & 54 GT & $61 \mathrm{GT}$ \\
\hline
\end{tabular}

Nota: *Em 1988, no primeiro simpósio da ANPEPP, os trabalhos não foram estruturados por GT, mas reunidos a partir dos programas de pós-graduação e seus pesquisadores. 
como cerne questões relacionadas aos processos de vulnerabilização social, tanto no que se refere à pobreza material, quanto às formas mais sofisticadas de exclusão, discriminação, marginalização ou institucionalização. Poder-se-ia relacionar essa produção a processos de exclusão que agem no corpo físico (pobreza), corpo político (discriminação/modos de produção) e no corpo psíquico (produção de sentidos).

Os grupos de trabalhos analisados são apresentados abaixo com o ano de seu início e término, quando foi o caso:

- Representações Sociais (1990-2010);

- Psicologia Comunitária (1990-2010);

- Comunidade Meio-Ambiente e Qualidade de Vida (1992-1996);

- Psicologia Política (e Movimentos Sociais) (1994-2010);

- Subjetividade Contemporânea (1998-2010);

- Subjetividade, Conhecimento e Práticas Sociais (1998-2010);

- Cotidiano e Práticas Sociais (2000-2010);

- Psicologia Sócio-Histórica e o Contexto Brasileiro de Desigualdade Social (2002-2010);

- Trabalho e Processos Organizativos na Contemporaneidade (2006-2010);

- Políticas de Subjetivação, Invenção do Cotidiano e Clínica da Resistência (2006-2010);

- Ócio, Tempo e Trabalho (2008-2010).

Os resumos dos GT foram dispostos na Tabela 2, permitindo uma melhor visualização das questões relacionadas a cada um dos temas de análise, bem como das mudanças ocorridas nos GT ao longo dos anos.

\section{Resultados e Discussão}

\section{Risco e vulnerabilidade social}

Inicialmente, importa conceituar melhor as expressões "risco social" e "vulnerabilidade social".

O conceito de risco social foi incorporado ao campo da saúde com os trabalhos realizados sobre a epidemia da Acquired Immunodeficiency Syndrome (AIDS, Síndrome de Imunodeficiência Adquirida). As primeiras discussões articulavam dois estratos de visibilidade: pessoas que eram discriminadas socialmente, tais como homossexuais e usuários de drogas; e a doença - AIDS -, associada ao medo e à moral. Essa composição inicial - grupos específicos que remetiam a questões de medo e moral -, levou à ampla disseminação do conceito de "grupo de risco" (Ayres, 1995). O enfoque de risco se constituiu um instrumento discriminador de diferentes probabilidades objetivas de danos a determinados indivíduos, famílias e grupos sociais. Esse enfoque ainda é bastante utilizado por diferentes instituições na organização e planejamento de suas ações, principalmente dentro do campo das políticas públicas, no qual essa expressão é utilizada para designar desde pessoas em condições de pobreza e que vivem em áreas de violência ou moradias construídas em locais com perigo de desaba-

Tabela 2

Instrumento de organização e análise dos GT

\begin{tabular}{|c|c|c|c|c|c|c|c|}
\hline \multirow{4}{*}{ 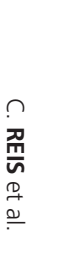 } & & \multicolumn{6}{|c|}{ Risco e Vulnerabilidade Social } \\
\hline & & \multicolumn{2}{|c|}{ I Simpósio 1988} & \multicolumn{2}{|c|}{ |l Simpósio 1989} & \multicolumn{2}{|c|}{ Anos seguintes } \\
\hline & & Histórico & Propostas & Histórico & Propostas & Histórico & Propostas \\
\hline & Nome do GT (Componentes) & $\begin{array}{l}\text { Detalhamento } \\
\text { do histórico } \\
\text { relacionado aos } \\
\text { temas }\end{array}$ & $\begin{array}{l}\text { Detalhamento da } \\
\text { proposta } \\
\text { relacionada aos } \\
\text { temas }\end{array}$ & & & & \\
\hline
\end{tabular}

586

Nota: GT: Grupos de Trabalho. 
mento ou redes de alta tensão, até mesmo questões como gravidez com possibilidade de aborto espontâneo (Mitjavila, 2002). Assim, o diagnóstico do risco social é possível pelo estabelecimento de uma interlocução entre saberes e instituições que vão produzir e sustentar um discurso verdadeiro, legitimado, não apenas sobre o risco, mas sobre uma normalidade das populações e sobre os modos ser, formar e educá-las. Produz-se um efeito de verdade não apenas em relação ao que é dito como risco, mas também legitimando as formas, modos, saberes e espaços de intervenção sobre ele, ou seja, as chamadas práticas de governamento (Hüning \& Guareschi, 2009).

Já o conceito de vulnerabilidade social se contrapõe à noção de grupo de/em risco, na medida em que a condição de vulnerável não remete ao indivíduo. A vulnerabilidade reside, não no indivíduo, mas na falta ou na não-condição de acesso a bens materiais e bens de serviço que possam suprir aquilo que pode torná-lo vulnerável (Abramovay, Castro, Pinheiro, Lima, \& Martinelli, 2002). Evidencia-se, a partir desses aspectos, um deslocamento na atribuição da condição de vulnerabilidade, que já não se constitui como característica própria do indivíduo, mas como resultado da combinação de determinados arranjos sociais e políticos que vão incidir sobre os sujeitos (Guareschi, Reis, Hüning, \& Bertuzzi, 2007). Como exemplo, têm-se as formulações sobre jovens em situação de vulnerabilidade social, que seriam, por exemplo, jovens de famílias de baixa renda que residem em territórios com presença de tráfico de drogas, o que traria a possibilidade de seu envolvimento em comportamentos ilícitos ou de sua exposição ao uso dessas substâncias. A questão central é que não são os jovens que são vulneráveis, mas sim a situação em que se encontram e que os expõe à vulnerabilidade. Em outras produções já se tem atribuído essa condição aos próprios territórios: são os "territórios vulneráveis", como os utilizados mais recentemente nas políticas de segurança pública, como por exemplo "Programa de Proteção aos Jovens em Territórios Vulneráveis".

A vulnerabilidade social dialoga também com noção de inserção social através do mercado de consumo, pois, de maneira geral, questões sobre exclusão remetem às populações que não têm acesso à renda ou aos meios de produção, que seriam, por exemplo, os moradores de rua ou as pessoas institucionalizadas. Por outro lado, esse também é um conceito amplamente debatido dentro da própria Psicologia Social, pois se entende que seria impossível estar de fato excluído da sociedade, uma vez que essas instituições e os processos de marginalização estão totalmente integrados à conjuntura social da sociedade capitalista atual. Além disso, reconhece-se que essas populações também são produtivas à economia de mercado, pois em torno delas se organiza uma série de ações e serviços (Castel, 1997).

Embora essas discussões e conceitualizações partam também do campo da Psicologia Social, é importante ressaltar que tais denominações são utilizadas pelos GT, em diversos momentos, de forma arbitrária e alheia a esses fundamentos.

Ainda que haja, na grande maioria dos grupos, uma tendência de dar visibilidade à questão da coletividade - como é o caso dos GT "Psicologia Comunitária" (ANPEPP, 1998) e "A Psicologia Sócio-Histórica e o Contexto Brasileiro de Desigualdade Social" (ANPEPP, 2004) -, existem algumas produções que mantêm o foco no indivíduo, trabalhando com a noção de risco em detrimento do conceito de vulnerabilidade social. Há, ainda, alguns casos em que ambas as denominações são utilizadas como sinônimos. Em outros casos, como o do GT "Representações Sociais" (ANPEPP, 1998), mantém-se a noção de risco, mas como possibilidade de produzir críticas em torno dessa noção, principalmente associada ao papel da mídia na proliferação de uma "cultura do risco" ligada à adolescência, crise, desordem, irresponsabilidade e problema social. Já no GT "Ócio, Tempo e Trabalho" (ANPEPP, 2008), por exemplo, tem-se uma perspectiva mais individualizada, que concebe o ócio seja como promotor de bem-estar, seja vinculado à ideia de risco social ou de ser seu potencializador. Ainda que essa noção ultrapasse o limite da individualidade e se instale no nível social, ao utilizar o conceito de risco, ela pode cair em uma perspectiva de moralização dos comportamentos individuais. 


\section{Compromisso Político da Psicologia Social}

Ao acompanhar as produções dos GT, evidencia-se que os estudos sobre a vulnerabilização, a pobreza e a exclusão social afirmam o compromisso político da Psicologia Social e sua implicação na construção de um projeto social. Esse compromisso político vem acompanhado pela crítica à suposta neutralidade da pesquisa em favor da busca de saberes que produzam transformações sociais. Essa perspectiva é transversal a quase todos os GT, e o que se modifica é apenas a forma como os diferentes GT abordam essas questões, o que está bastante vinculado à perspectiva epistemológica que fundamenta suas pesquisas.

Ao eleger as populações de baixa renda ou aquelas alvo de processos de discriminação e marginalização como foco de estudos, Os GT "Psicologia Política" (ANPEPP, 2000), "Psicologia Comunitária" (ANPEPP, 2004) e "Representações Sociais" (ANPEPP, 2004), por exemplo, mostram a importância de a Psicologia Social estar em consonância com as problemáticas sociais, buscando a produção de pesquisas engajadas em processos de formação de lideranças, mobilização social, desalienação e envolvimento político. Os GT de "Psicologia Política" (ANPEPP, 2000) e "Representações Sociais" (ANPEPP, 1990), trabalhando com a noção de poder pautada por relações hierárquicas de dominação, produz pesquisas vinculadas a um projeto de mudança nessas relações.

Já os grupos de trabalhos vinculados a uma perspectiva pós-estruturalista, como os GT "Cotidiano e Práticas Sociais" (ANPEPP, 2002), "Subjetividade, Conhecimento e Práticas Sociais" (ANPEPP, 2002), "Políticas de Subjetivação, Invenção do Cotidiano e Clínica da Resistência" (ANPEPP, 2008) e "Subjetividade Contemporânea" (ANPEPP, 2000) têm como foco estudos sobre os modos de produção da experiência subjetiva. Ao afirmarem a dimensão política da ciência, reconhecem a estreita relação entre saberes e poderes, implicados no modo pelo qual um determinado conjunto de práticas sociais produz certas formas de ser e estar no mun- que buscam ser agentes de intervenção, como a pesquisa participante, a pesquisa intervenção e a pesquisa ação.

Além disso, alguns desses últimos GT procuram problematizar a própria produção do conhecimento em Psicologia. O GT "Políticas de Subjetivação, Invenção do Cotidiano e Clínica da Resistência" (ANPEPP, 2010), por exemplo, critica a produção dos campos de saberes, afirmando que as relações entre pesquisa, formação e intervenção nas dimensões macro e micropolíticas podem resultar não só em formas de submissão, mas também de resistência.

Ainda no que se refere à questão do compromisso social da Psicologia, é interessante ressaltar que o GT "Psicologia Comunitária" sofre uma ruptura no ano de 1998, como efeito das diferentes visões de seus membros a respeito das formas como a pesquisa deve, ou não, estar implicada em transformações políticas e sociais. A partir dessa ruptura, alguns membros do GT passam a compor o Grupo "Comunidade, Meio-Ambiente e Qualidade de Vida" (ANPEPP, 1998). Nas produções desse último GT, são referidas preocupações quanto ao crescimento dos estudos pós-modernistas dentro do campo da psicologia comunitária. Para os membros do Grupo, ao romper com a modernidade, esses estudos poderiam perder a cientificidade da pesquisa. Nos resumos do GT, os pesquisadores afirmam a necessidade de afastar pesquisas com "comprometimento ideológico e político-demagógico" e referem que a psicologia comunitária não pode trabalhar somente com comunidades carenciadas, pois entendem que o espírito comunitário também está presente em outros grupos, partindo para uma perspectiva de comunidade como grupo populacional ou cultural. Esse GT deixa de trabalhar com a noção de transformação social e passa a pensar na melhoria da qualidade de vida, o que o difere do GT "Psicologia Comunitária", que mantém a afirmação de produzir melhorias nas condições de vida, em uma referência direta à superação da pobreza.

Esse processo de ruptura e reorganização dos Grupos de Trabalho é emblemático de um movimento que pode ser observado ao longo dos 
anos nas análises de todos os GT. Embora os grupos afirmem a importância de trabalhar com a diversidade teórica, o que ocorre é uma divisão dos Grupos ou a troca de alguns pesquisadores, quando diferentes perspectivas epistemológicas ficam mais evidenciadas. Ressaltando-se que esse não é o único motivo de trocas e divisões de grupos, outros fatores são as mudanças de interesse dos pesquisadores em relação a determinadas temáticas ou ainda o aumento significativo de pesquisadores em um mesmo grupo. De qualquer forma, todos esses movimentos parecem dirigir os GT para especificidades tanto teóricas quanto temáticas.

\section{Produção de categorias sociais}

Ao tomar a pobreza e os processos de vulnerabilização e marginalização social como objeto de estudo, os GT passam a ter como foco determinados grupos populacionais. Embora se afirme que as pesquisas têm como intuito reconhecer as diferenças produzidas no campo social e promover o respeito à alteridade, ao tomar essas populações como objeto de estudo, a Psicologia passa também a produzir verdades sobre esses sujeitos que objetiva conhecer/descrever. Um dos efeitos desse movimento é a produção de saberes em torno dessas populações, que passam a ter seus modos de vida reconhecidos como vulneráveis ou em situação de risco social, o que circularmente legitima a segmentação da população em categorias populacionais.

Dentro dessa perspectiva, o conceito de risco articula-se a marcadores, tais como comportamento e populações específicas. Essa estratégia individualiza certas condições e possibilita o desenvolvimento de formas de governamentalidade dessas populações por meio de biopolíticas centradas em marcadores identitários. Já a objetivação da vulnerabilidade social desloca-se para a esfera da vida social, na medida em que se refere às condições de vida e suportes sociais, e não à conduta, como marcava o conceito de risco. Ainda, considerando que a vulnerabilidade não se restringe à categoria econômica, passando por organizações políticas de raça, orientação sexual, sexo e etnia, destaca-se que as organizações simbólicas também estão intima- mente ligadas ao conceito de vulnerabilidade social (Sanchéz \& Bertolozzi, 2007). Embora se refira às condições de vida e não aos comportamentos individuais, a noção de vulnerabilidade social, assim como a noção de risco social, oferece mecanismos que permitem categorizar indivíduos, famílias ou situações, que servem de apoio para tomar decisões que afetam a vida das organizações e das pessoas.

Os estudos sobre risco e vulnerabilidade abriram caminho para a construção de estratégias de "contagem dos pobres" (Castel, 1997) e de mecanismos de produção de recortes populacionais que vieram legitimar a identificação de determinados grupos como categorias sociais de risco. Assim, esses estudos constituíram-se como instrumento de gestão que auxiliam no desenvolvimento de políticas públicas e sociais destinadas aos ditos vulneráveis, procurando incidir na melhoria das condições de acesso dessas populações a bens e serviços. Em torno dos diferentes níveis de pobreza e exclusão social, foram se construindo diferentes estratégias de intervenção e de organização dos marginalizados.

A produção de saberes em torno de determinados grupos populacionais pode ser vista em quase todos os GT trabalhados. O GT "Subjetividade Contemporânea" (ANPEPP, 2010), por exemplo, trabalha com doentes mentais, autistas, drogaditos e jovens que cometeram ato infracional, enquanto o GT "Comunidade, Meio-Ambiente e Qualidade de Vida" (ANPEPP, 1998), por exemplo, trabalha com migrantes nordestinos, pequenos agricultores, doentes mentais e questões de gênero. 0 GT "Psicologia Política e Movimentos Sociais" (ANPEPP, 1990), por fim, trabalha com as questões raciais e de gênero/homofobia. São esses recortes das populações-alvo que permitem a sofisticação na mobilização de recursos, especialistas e instituições, com maiores níveis de complexidade para atender aos problemas particulares desses grupos. É, portanto, a produção de conhecimento sobre vulnerabilidade e risco que vai embasar grande parte das discussões para a constituição de políticas públicas e sociais, apresentadas como instrumento de promoção de melhoria nas condições de vida. 


\section{Dos movimentos sociais às políticas públicas como foco de transformação social}

A construção de saberes militantes na Psicologia Social investe, inicialmente, nos movimentos sociais e nas lideranças comunitárias como atores de mudanças. Entretanto, ao longo dos anos, esse investimento vai sofrendo um deslocamento, que passa a reconhecer as políticas públicas como protagonistas do processo de transformação social, inclusive com a posição de alguns GT, desde muito cedo. Embora esse deslocamento não iniba os estudos com foco nos movimentos sociais, o que se observa, após 2000, é um volume muito maior de trabalhos direcionados para as políticas públicas, e progressivamente menor para os movimentos sociais. Uma das hipóteses possíveis para esse deslocamento se refere à própria constituição das políticas públicas como importante espaço de inserção profissional para a Psicologia nesses últimos 10 anos (desde os anos 2000 quando observa-se o aumento expressivo de produções dos GT sobre as políticas públicas, até o ano de 2010, período de abrangência do material de análise da pesquisa), o que gerou um maior investimento das agências de fomento em pesquisas nessas áreas, juntamente com um maior interesse dos pesquisadores nesse foco. O que chama atenção em relação a isso é que um dos riscos que se tem quando só se opera pela via do Estado é o enfraquecimento da noção de que a política se refere às relações entre as pessoas, com isso, podendo despotencializar os modos de organização populares.

O próprio grupo de trabalho "Psicologia Política e Movimentos Sociais" (ANPEPP, 1994) traz estudos relacionados aos movimentos sociais e sua cooptação pela política governamental. Esse GT trabalha com política na forma como ela se institucionaliza nas estruturas governamentais, parlamentares e partidárias, não se referindo à noção de política como as relações entre os sujeitos sociais. Define o movimento social como ações organizadas para promover mudanças nas relações de poder na sociedade, tendo como objetivo último a tomada de poder pelo Estado.
Já o grupo de trabalho "Psicologia Comunitária", que tem um forte direcionamento para os movimentos sociais e o desenvolvimento de lideranças comunitárias, entre os anos de 2002 e 2004 passa a direcionar seu foco para as políticas públicas como mecanismo de transformação social e de superação das condições geradoras de marginalidade, exclusão e opressão sociais. Esse mesmo GT, em 2008 e 2010, já aparece com enfoque totalmente voltado para as políticas públicas. Outros GT como "Cotidiano e Práticas Sociais" e "A Psicologia Sócio-Histórica" e o "Contexto Brasileiro de Desigualdade Social", ambos constituídos após os anos 2000, também apresentam discussões mais voltadas para as políticas públicas (ANPEPP, 2000). Além deles, o GT "Psicologia Política e Movimentos Sociais", no ano de 2006, relata que está passando por mudanças no sentido de que alguns pesquisadores passam a tomar como foco a participação social no âmbito das políticas públicas (ANPEPP, 2006).

Esse deslocamento parece promover uma despolitização e institucionalização dos movimentos sociais: diminuem os estudos direcionados a esses grupos, em favor do foco nas práticas psicológicas produzidas em organizações agora nomeadas como governamentais ou não-governamentais. Os movimentos sociais, que foram os protagonistas para a construção do projeto de democratização do país, perdem sua potência no cenário da Psicologia Social contemporânea. Além disso, observa-se que, ao tomar as políticas públicas como foco, os estudos dos GT analisados direcionam-se expressivamente para a busca de soluções funcionalistas, que visam o bem operar dos serviços públicos, procurando oferecer respostas aos profissionais e gestores acerca dos entraves impostos à efetivação dos marcos legais já consolidados.

\section{Micropolíticas e produção de subjetividades}

Ainda, por volta de 2000, observa-se a proliferação de GT focados não mais na construção de mudanças macropolíticas, mas nos processos de subjetivação como possibilidade de promoção de 
mudanças nos modos de vida e no campo social. Além disso, os GT passam a refletir sobre os modos de subjetivação que estão sendo produzidos por determinados discursos hegemônicos sobre risco e vulnerabilidade social.

Essa é uma perspectiva de grupos mais próximos a um paradigma epistemológico pósestruturalista, como o GT "Cotidiano e Práticas Sociais", o GT "Subjetividade, Conhecimento e Práticas Sociais" e o GT "Políticas de Subjetivação, Invenção do Cotidiano e Clínica da Resistência". Esses GT trazem discussões como os efeitos das políticas públicas nos modos de subjetivação, a violência institucionalizada, a associação entre violência e pobreza, a desqualificação das famílias pobres, produzida pelas políticas públicas. O GT "Políticas de Subjetivação, Invenção do Cotidiano e Clínica da Resistência" (ANPEPP, 2006) trabalha com a perspectiva de cartografar novas formas de produção subjetiva, no intuito de desestabilizar certezas e verdades científicas que produzem exclusão. Da mesma forma, o GT "Cotidiano e Práticas Sociais", em 2004, trabalha com a mídia impressa, trazendo como foco a desnaturalização das desigualdades e diferenças no âmbito da produção de subjetividades (ANPEPP, 2004). Já o GT "Subjetividade Contemporânea" (ANPEPP, 2000) produz estudos sobre como as transformações contemporâneas no trabalho e na organização do espaço público pode produzir processos de exclusão social. Ainda, estuda a produção de subjetividade nas políticas públicas, através das noções de vulnerabilidade, miséria, pobreza e marginalização.

A perspectiva que está posta aqui é a de que as exclusões não se produzem só pela vulnerabilização do corpo físico e da exposição do sujeito à morte biológica, mas também se produzem pela restrição da potência de vida dos sujeitos e pela restrição das diferentes formas de ser e habitar a contemporaneidade. Nesse sentido, a transformação social não passa somente pela necessidade de superação da pobreza, mas está relacionada aos modos como os sujeitos se relacionam consigo mesmo e com o mundo. Nesse sentido, essas produções destinam-se a problematizar as próprias políticas públicas e as práticas psicológicas.
À medida que a produção de conhecimento sobre risco e vulnerabilidade social vai sendo politizada, no sentido de romper com uma historicidade crítica sobre esses conceitos, passando também para uma análise de dessubstancialização de populações e identidades sociais, emergem produções de saberes nos GT de Psicologia Social, que trazem à cena a transversalidade dos movimentos sociais, evidenciando os efeitos das práticas de políticas públicas na produção e governamento dos modos de vida dos sujeitos.

\section{Caminhos para refletir sobre o compromisso político e social da Psicologia}

Ao percorrer os registros das pesquisas e conhecimentos produzidos nos GT da ANPEPP, este estudo buscou dar visibilidade a outro modo de se pensarem os percursos históricos da Psicologia Social no Brasil. Destacou-se a forma como, a partir das produções sobre as temáticas de risco e vulnerabilidade social como propulsoras de estudos no campo da Psicologia Social, e com base na análise arqueogenealógica, foi possível tornar visíveis as rupturas e diferenças entre as diversas posições dos saberes.

A presente análise apontou os modos como as temáticas de risco e vulnerabilidade foram sendo tomadas e produzidas pela Psicologia Social, suscitando, muitas vezes, movimentos paradoxais. Notou-se, por vezes a imprecisão, por vezes a especificidade com que se buscou demarcar cada um desses termos. Transversalizaram essa discussão a responsabilização individual ou coletiva pelas situações de risco/vulnerabilidade, bem como a resposta da Psicologia Social a partir de um discurso de compromisso social e político. No entanto, a mesma produção que se afirmou implicada com tais compromissos sociais, ao tomar como objeto determinados grupos sociais, reafirmou a produção de categorias que, muitas vezes, reiteravam a condição de risco/ vulnerabilidade que se dizia buscar enfrentar. Outro elemento relevante nesta análise foi o movimento dos saberes da Psicologia Social sobre risco/vulnera- 
bilidade, que se iniciaram com estudos sobre movimentos sociais e se direcionaram para trabalhos sobre políticas públicas. Por fim, destacou-se a emergência de discussões sobre risco/vulnerabilidades, que se deslocaram do campo macropolítico para os processos micropolíticos de subjetivação.

Ao recusar-se a olhar para a construção de seu campo de saber através da linearidade histórica, esta pesquisa evitou o risco de cair em uma avaliação evolucionista dos paradigmas epistemológicos que dão sustentação à Psicologia Social. Além disso, esse método permitiu evidenciar as linhas de força, descontinuidades e relações com os objetos de estudo e seus efeitos para a construção desse campo, desenhando assim não uma história encerrada, mas aquilo que a coloca em movimento.

Dito de outro modo, este estudo pôde evidenciar o caráter político das pesquisas em Psicologia Social, que passam a ser produzidas ao mesmo tempo que produzem temáticas: não a partir do mero progresso do conhecimento, mas dos modos como se forjam as novas configurações sociais. Ao narrar a história da Psicologia Social a partir dessas produções (o que não implica uma recusa absoluta de outras formas de narrativas históricas), esta pesquisa pôde constituir outro olhar sobre a trajetória desse campo de conhecimento e sobre seu envolvimento com questões em evidência, como as políticas públicas.

\section{Referências}

Abramovay, M., Castro, M. G., Pinheiro, L. C., Lima, F. S., \& Martinelli, C. C. (2002). Juventude, violência e vulnerabilidade social na América Latina: desafios para políticas públicas. Brasília: Unesco.

Associação Nacional de Pesquisa e Pós-Graduação em Psicologia. (1989). Anais do /l Simpósio Brasileiro de Pesquisa e Intercâmbio Científico da ANPEPP. Recuperado em junho 7, 2014, de http://www.infocien.org/ Interface/Simpo02.htm

Associação Nacional de Pesquisa e Pós-Graduação em Psicologia. (1990). Anais do III Simpósio Brasileiro de Pesquisa e Intercâmbio Científico da ANPEPP. Recuperado em junho 7, 2014, de http://www.infocien.org/ Interface/Simpo03.htm
Associação Nacional de Pesquisa e Pós-Graduação em Psicologia. (1992). Anais do IV Simpósio Brasileiro de Pesquisa e Intercâmbio Científico da ANPEPP. Recuperado em junho 7, 2014, de http://www.infocien.org/ Interface/Simpo04.htm

Associação Nacional de Pesquisa e Pós-Graduação em Psicologia. (1994). Anais do V Simpósio Brasileiro de Pesquisa e Intercâmbio Científico da ANPEPP. Recuperado em junho 7, 2014, de http://www.infocien.org/ Interface/Simpo05.htm

Associação Nacional de Pesquisa e Pós-Graduação em Psicologia. (1996). Anais do VI Simpósio Brasileiro de Pesquisa e Intercâmbio Científico da ANPEPP. Recuperado em junho 7, 2014, de http://www.infocien.org/ Interface/Simpo06.htm

Associação Nacional de Pesquisa e Pós-Graduação em Psicologia. (1998). Anais do VII Simpósio Brasileiro de Pesquisa e Intercâmbio Científico da ANPEPP. Recuperado em junho 7, 2014, de http://www.infocien.org/ Interface/Simpo07.htm

Associação Nacional de Pesquisa e Pós-Graduação em Psicologia. (2000). Anais do VIII Simpósio Brasileiro de Pesquisa e Intercâmbio Científico da ANPEPP. Recuperado em junho 7, 2014, de http://www.infocien.org/ Interface/Simpo08.htm

Associação Nacional de Pesquisa e Pós-Graduação em Psicologia. (2002). Anais do IX Simpósio Brasileiro de Pesquisa e Intercâmbio Científico da ANPEPP. Recuperado em junho 7, de 2014, de http://www.infocien.org/ Interface/Simpo09.htm

Associação Nacional de Pesquisa e Pós-Graduação em Psicologia. (2004). Anais do X Simpósio Brasileiro de Pesquisa e Intercâmbio Científico da ANPEPP. Recuperado em junho 7, de 2014, de http://www.anpepp. org.br/old/5-Simposios/simposios-X.htm

Associação Nacional de Pesquisa e Pós-Graduação em Psicologia. (2006). Anais do XI Simpósio Brasileiro de Pesquisa e Intercâmbio Científico da ANPEPP. Recuperado em junho 7, de 2014, de http://www.anpepp.org. br/old/5-Simposios/simposios-XI.htm

Associação Nacional de Pesquisa e Pós-Graduação em Psicologia. (2008). Anais do XII Simpósio Brasileiro de Pesquisa e Intercâmbio Científico da ANPEPP. Recuperado em junho 7, de 2014, de http://www.anpepp. org.br/old/5-Simposios/simposios-XII.htm

Associação Nacional de Pesquisa e Pós-Graduação em Psicologia. (2010). Anais do XIII Simpósio Brasileiro de Pesquisa e Intercâmbio Científico da ANPEPP. Recuperado em junho 7, de 2014, de http://www.anpepp. org.br/old/5-Simposios/simposios-XIII.htm

Associação Nacional de Pesquisa e Pós-Graduação em Psicologia. (2012, maio). Simpósios [trabalhos apresentados]. Recuperado em maio 10, 2012, de http:// www.anpepp.org.br/1-Acervo/pri-acervo.htm 
Ayres, J. R. C. M. (1995). O enfoque de risco na programação em saúde: fundamentos e perspectivas. Saúde e Sociedade, 4(1-2), 71-74.

Castel, R. (1997). A dinâmica dos processos de marginalização: da vulnerabilidade a "desfiliação". Caderno $\mathrm{CRH}, 10(26 / 27), 19-40$.

Hüning, S., \& Guareschi, N. (2009). A cidade precisa dormir em paz: relações entre educação psicologia e risco social. Cadernos de Educação, 32, 41-62.

Foucault, M. (2007). Microfísica do poder. Rio de Janeiro: Edições Graal. (Originalmente publicado em 1979).

Foucault, M. (2009). A arqueologia do saber. Rio de Janeiro: Forense Universitária. (Originalmente publicado em 1969).
Guareschi, N. M. F., Reis, C. D., Hüning, S. M., \& Bertuzzi, L. D. (2007). Intervenção na condição de vulnerabilidade social: um estudo sobre a produção de sentidos com adolescentes do programa do trabalho educativo. Estudos e Pesquisas em Psicologia, 7(1), 17-27.

Mitjavila, M. (2002). O risco como recurso para a arbitragem social. Tempo Social, 14(2), 129-145.

Sánchez, A. I. M., \& Bertolozzi, M. R. (2007). Pode o conceito de vulnerabilidade apoiar a construção do conhecimento em Saúde Coletiva? Ciência e Saúde Coletiva, 12(2), 319-324.

Recebido em: 8/1/2013

Aprovado em: 19/3/2013 
